\title{
Simulation of blue and green water resources in the Wei River basin, China
}

\section{ZONGXUE XU \& DEPENG ZUO}

Key Laboratory of Water and Sediment Sciences, Ministry of Education, College of Water Sciences, Beijing Normal University, Beijing 100875, China

zongxuexu@vip.sina.com

\begin{abstract}
The Wei River is the largest tributary of the Yellow River in China and it is suffering from water scarcity and water pollution. In order to quantify the amount of water resources in the study area, a hydrological modelling approach was applied by using SWAT (Soil and Water Assessment Tool), calibrated and validated with SUFI-2 (Sequential Uncertainty Fitting program) based on river discharge in the Wei River basin (WRB). Sensitivity and uncertainty analyses were also performed to improve the model performance. Water resources components of blue water flow, green water flow and green water storage were estimated at the HRU (Hydrological Response Unit) scales. Water resources in HRUs were also aggregated to sub-basins, river catchments, and then city/region scales for further analysis. The results showed that most parts of the WRB experienced a decrease in blue water resources between the 1960s and 2000s, with a minimum value in the 1990s. The decrease is particularly significant in the most southern part of the WRB (Guanzhong Plain), one of the most important grain production basements in China. Variations of green water flow and green water storage were relatively small on the spatial and temporal dimensions. This study provides strategic information for optimal utilization of water resources and planning of cultivating seasons in the Wei River basin.
\end{abstract}

Key words blue water; green water; SWAT; SUFI-2; Wei River, China

\section{INTRODUCTION}

Renewable freshwater is the foundation for life in terrestrial and freshwater ecosystems (Jackson et al. 2001). In China, almost all the river basins in the northern areas are experiencing a shortage of water resources, leading to the degradation of economic and environmental sustainability. The situation endured in the Yellow River basin and its tributaries, notably the Wei River basin (WRB), is particularly serious (Yang et al. 2004).

The concepts of blue water and green water were firstly introduced by Falkenmark (1995), and developed by others. By definition, blue water is the sum of surface runoff and deep aquifer recharge. Green water flow is the actual evapotranspiration (AET) released to the atmosphere through a combination of evaporation from soil and water bodies, and transpiration from vegetation. Green water storage (soil moisture) is the amount of water in the soil profile at the end of a time-period. There have been many studies quantifying the green and blue water resources since the advent of the concept. For instance, Gerten et al. (2005) and Rost et al. (2008) used the LPJ/LPJmL model to estimate global green and blue water consumption over the past 30 years. Schuol et al. (2008) and Faramarzi et al. (2009) adopted the SWAT model to simulate blue and green water resources in Africa and Iran, respectively. Liu et al. (2009) quantified the effect of land use and land cover changes on green water and blue water in the northern part of China. Zang et al. (2012) simulated spatial and temporal patterns of both blue and green water flows by the SWAT model for the Heihe River basin. Hydrological models can provide more insights into the mechanisms of land surface and hydrological processes, and are regarded as a powerful tool for simulating hydrological processes and assessing water resources spatiotemporally. Among the aforementioned models, the SWAT model is one that can be applied to a large ungauged basin for quantitatively determining the spatiotemporal variation of water resources (Arnold et al. 1998).

The objective of this study is to calibrate and validate the SWAT model in the WRB of China on a monthly time step with uncertainty analysis. Water resources availability is estimated at HRU, river catchment and city/region scales. The results will contribute to a better understanding of the paradigm of blue and green water resources and consequently provide useful information for the planning and management of water resources in the WRB. 


\section{STUDY AREA DESCRIPTION}

The Wei River (Fig. 1) originates from the Niaoshu Mountain, flows through the provinces of Gansu, Ningxia and Shaanxi, and runs into the Yellow River at Tongguan. The basin is located between $104^{\circ} 00^{\prime} \mathrm{E}-110^{\circ} 20^{\prime} \mathrm{E}$ and $33^{\circ} 50^{\prime} \mathrm{N}-37^{\circ} 18^{\prime} \mathrm{N}$, with a length of $818 \mathrm{~km}$ and a drainage area of 1.35 $\times 10^{5} \mathrm{~km}^{2}$. The Loess Plateau is located in the north, and the Qinling Mountains are located in the south, while a transition from high to low altitudes is observed from the west to the east part of the basin. The WRB is located in a semi-arid area with temperate continental monsoon climate. The mean air temperature is $7.8-13.5^{\circ} \mathrm{C}$, mean annual precipitation is $400-800 \mathrm{~mm}$, potential evapotranspiration is $800-1000 \mathrm{~mm}$, mean runoff is $195 \mathrm{~m}^{3} / \mathrm{s}$, and the runoff coefficient varies within $0.1-0.2$ (Zuo et al. 2012).

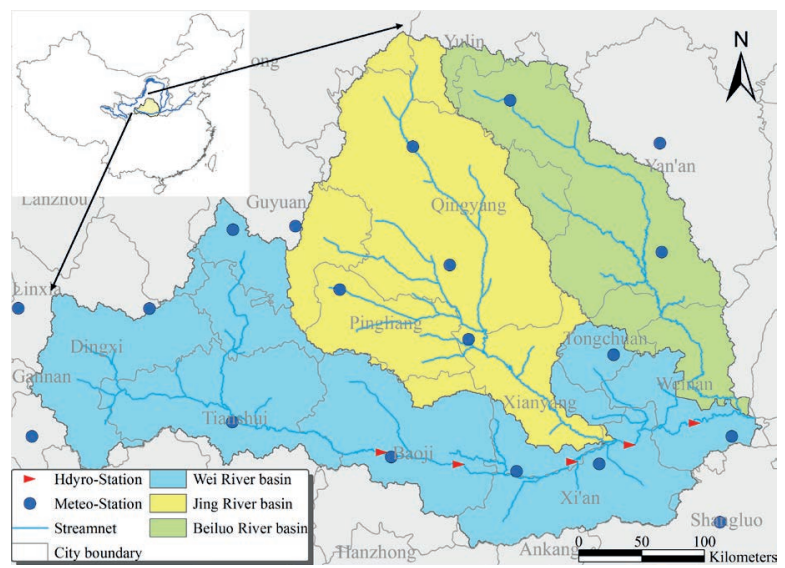

Fig. 1 Location of the WRB, and meteorological and hydrological stations used in this study.

\section{MODEL DESCRIPTION}

SWAT is a process-based and time continuous hydrological model operating at a daily scale. The model is semi-distributed and allows simulation of a high level of spatial detail by dividing the basin into a large number of sub-basins and HRUs (Arnold et al. 1998). The main components of SWAT include hydrology, climate, nutrient cycling, soil processes, sediment movement, crop growth, agricultural management and pesticide dynamics. Further technical details on the model are given by Neitsch et al. (2005).

SUFI-2 procedure was used for calibration and uncertainty analysis in this study. Overall uncertainty for the output is quantified by the $95 \%$ prediction uncertainty (95PPU). Two indices are used to quantify the goodness of calibration/uncertainty performance: P-factor, which is the percentage of measured data bracketed by the 95PPU band, and $R$-factor, which is the average width of the band divided by the standard deviation of the corresponding measured variable (Abbaspour et al. 2007).

In this study, the DEM, land use and soil map were provided by the Data Center for Resources and Environmental Sciences, Chinese Academy of Sciences (RESDC). Daily meteorological data series were obtained from China Meteorological Data Sharing Services System Network for 21 stations from 1961 to 2008. Daily discharge data series were obtained from the Yellow River Conservancy Commission (YRCC) for five gauging stations. The study area was divided into 106 sub-basins and 565 HRUs.

\section{RESULTS ANALYSIS}

\section{Model calibration and uncertainty analysis}

Sensitivity analysis results showed that most of the 28 global parameters related to hydrology were sensitive to river discharge. As expected, parameters such as CN2 (SCS runoff curve number), ALPHA_BF (Baseflow alpha factor) were the most sensitive parameters. We initially calibrated the 
model based on annual river discharge, and then the model was calibrated based on monthly measured data at five main gauging stations in the WRB. The $R$-factors for both calibration and validation at five stations are quite small. However, the $P$-factor for the calibration at Linjiacun and Weijiabao stations is small, which indicates that the actual uncertainty is larger than expected. In general, during the calibration (validation) period, $\Phi$ and $E_{N S}$ values at most of the stations were greater than $0.6(0.7)$, and $R^{2}$ at all stations was greater than $0.7(0.8)$, which indicates a satisfactory performance of the SWAT model in the WRB.
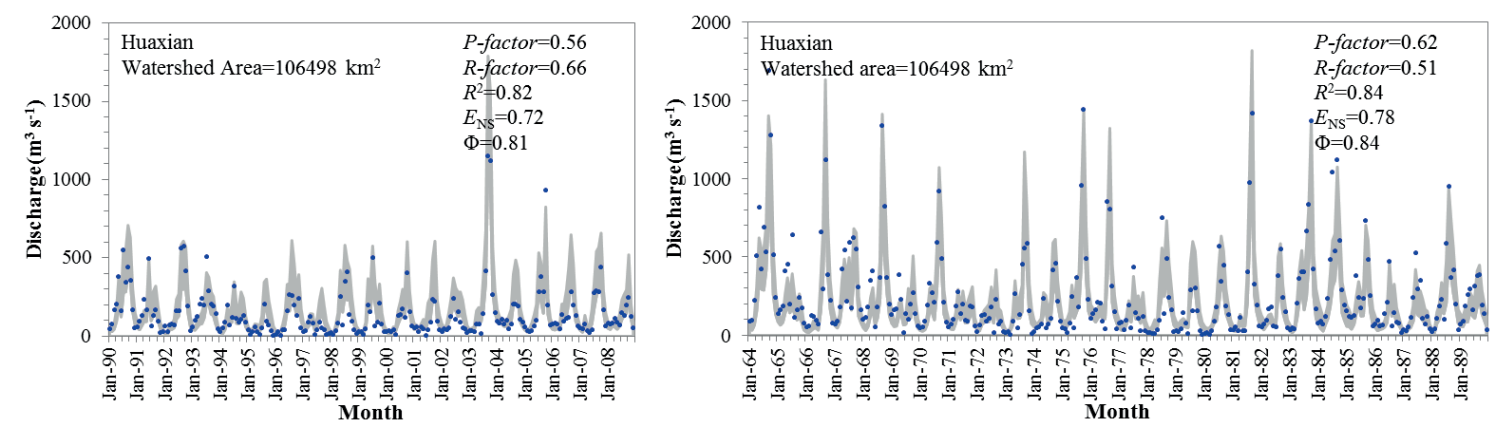

Fig. 2 Comparison between the measured (dots) and simulated (95PPU band, shaded area) monthly hydrographs at Huaxian station for both calibration (left) and validation (right) period.
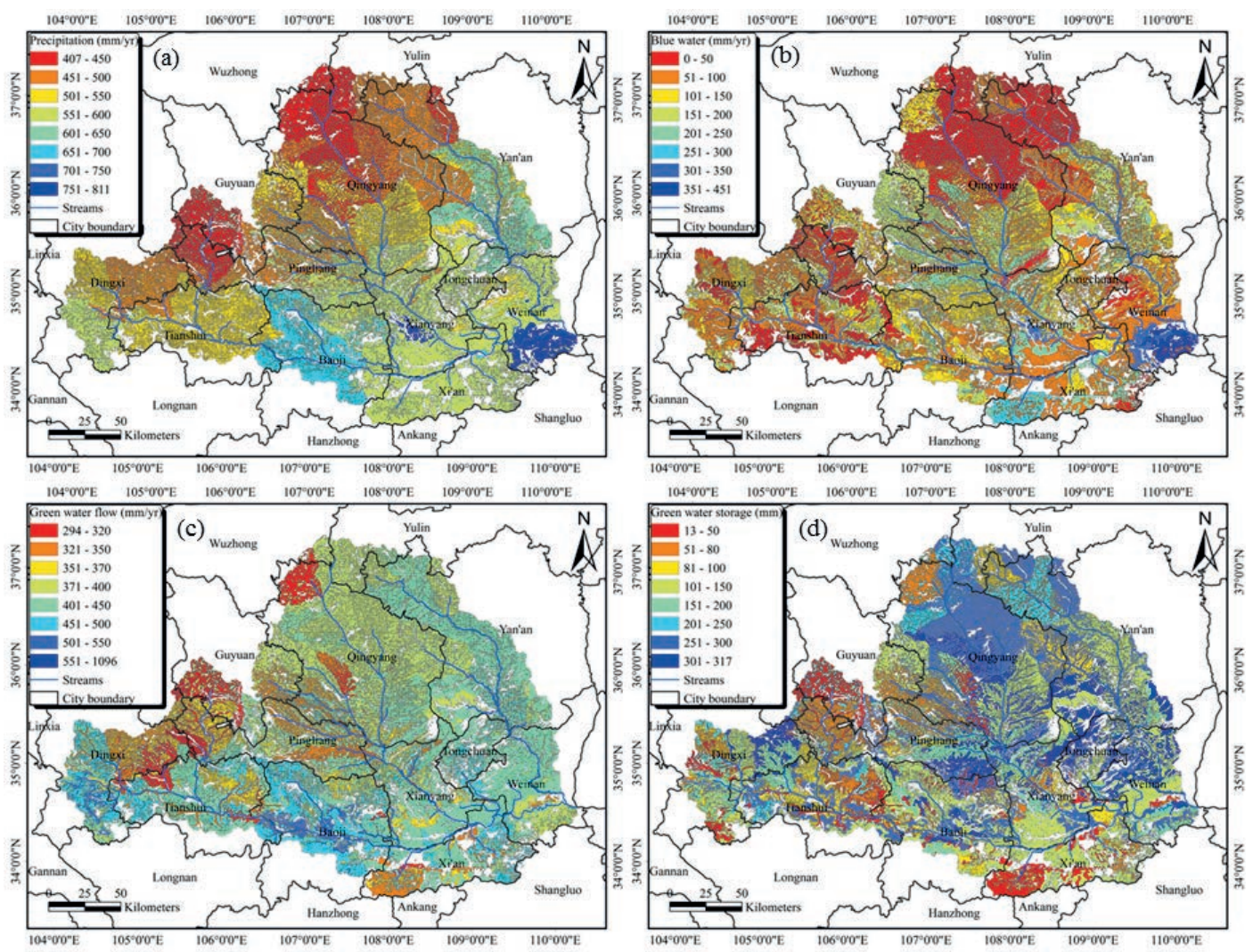

Fig. 3 Spatial distributions of the mean 95PPU ranges of annual precipitation (a), blue water (b), green water flow (c), and green water storage (d) on the HRU scale in the WRB during 1964-2008.

\section{Water resources availability at $\mathrm{HRU}$ scale}

Annual and monthly blue water flow, green water flow, and green water storage were estimated for all 565 HRUs using the calibrated model. Furthermore, annual and monthly water resources for different HRU were aggregated to estimate water resources availability at the river catchment and city/region scales. 
In order to show the spatial distribution of each water resources component, the simulation at the 50\% probability level for the period of 1964-2008 were used to characterize the spatial distribution of blue water flow, green water flow and green water storage for each HRU. The graphs are given in Fig. 3. For precipitation, average annual values for each HRU were estimated from the closest station.

In general, significant differences existed in the spatial distribution of water resources components across the whole WRB. Most parts of the WRB are experiencing serious blue water scarcity, especially for the Loess Plateau in the north. As expected, blue water flow in the upper region was generally less than that in the lower region. The spatial distribution of green water flow was similar to precipitation pattern, increasing from northwest to southeast. The green water storage map exhibited large spatial variability in the study area, comparing with the land cover and precipitation. This can be generally characterized by the denser vegetation cover and the greater rainfall. The green water storage is larger in the middle reaches of the Wei River and the lower reaches of the Beiluo River. It indicates that the two regions have relatively sufficient precipitation and green water resources, which are beneficial for the development of rain-fed agriculture.

\section{Water resources availability at river catchment scale}

Besides the spatial distribution, the inter- and intra-annual variability of water resources availability is also of great importance for water resources planning. Average annual blue water in the Wei River and Jing River is greater than that in the Beiluo River catchment, while the values of three river catchments all decreased significantly from the 1960s to the 2000s (Fig. 4). The magnitude of uncertainty for average annual blue water resources is wide, while annual precipitation is high. A similar conclusion was found by Faramarzi et al. (2009). The magnitude of green water flow in different catchments is relatively stable, partly due to the relatively stable land cover in the study area. The tendency of green water storage in each river catchment is similar to blue water flow, and the values in the Wei River are not as great as those in the Jing River and Beiluo River catchments.

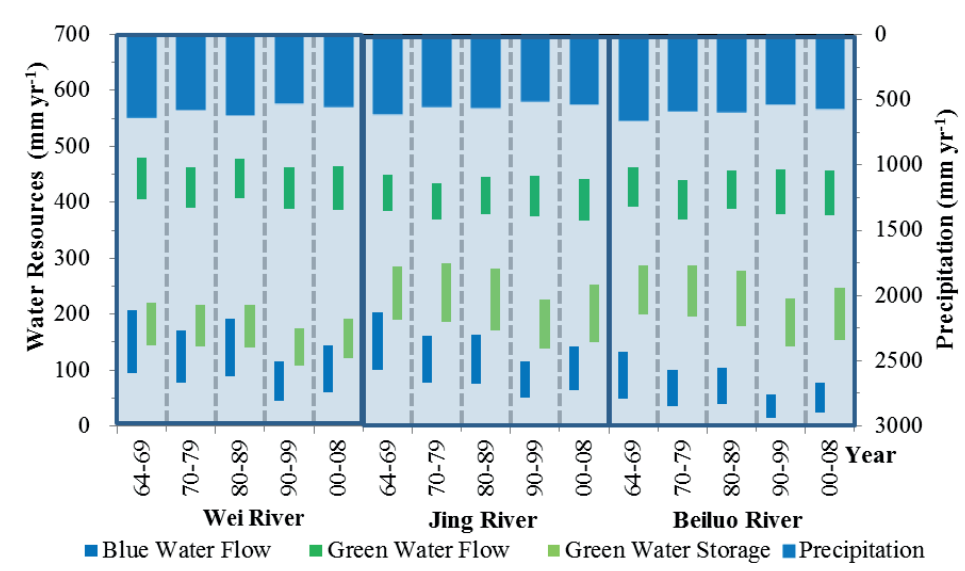

Fig. 4 Average annual blue water flow, green water flow and green water storage with 95PPU and precipitation for various decades in the Wei River, Jing River and Beiluo River catchments.

Blue water flow in three river catchments (Fig. 5) shows great uncertainties during the flood season (July-October). The blue water flow reaches the maximum in September, instead of July, during which the largest precipitation occurred. A delay between the peak of precipitation and the peak of river discharge exists. This is because of higher evapotranspiration in July and August, resulting in smaller runoff in the Guanzhong Plain in the south and the Loess Plateau in the north of the WRB. The volume in the Jing River and Beiluo River are larger than that in the Wei River, which means that the Loess Plateau may maintain relatively sufficient green water storage. The soil water storage appears to be larger in late summer and early autumn. This can be helpful for agriculture in months with less precipitation. The information will be useful for planning cultivation seasons and will provide a basis for water resources management. 

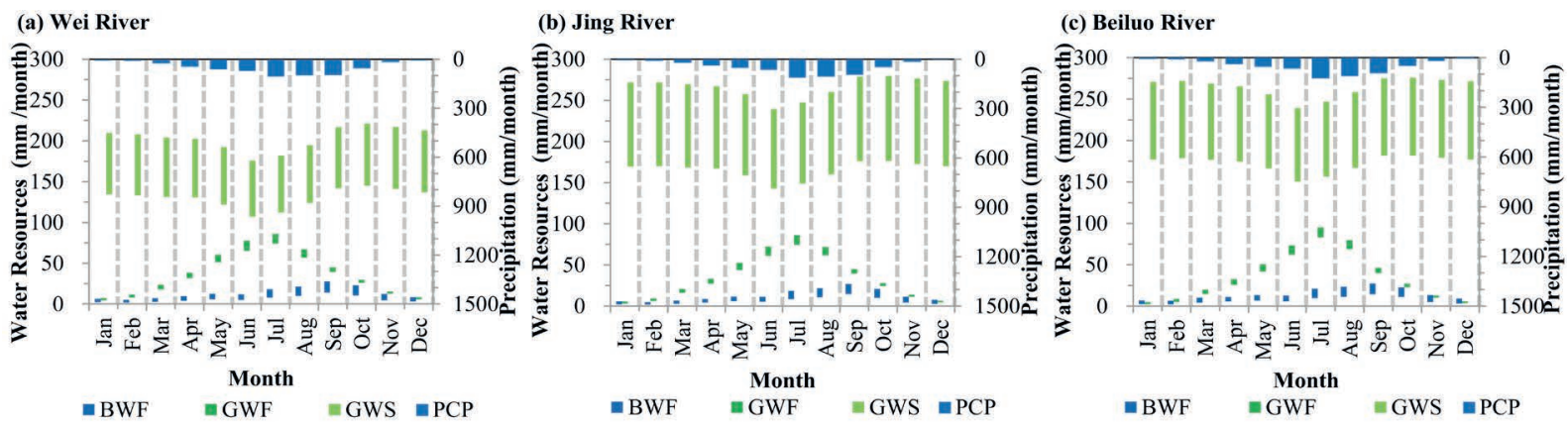

Fig. 5 Average (1964-2008) monthly 95PPU ranges of the blue water flow, the green water flow, and the green water storage in the Wei River (a), Jing River (b), and Beiluo River (c) catchments.

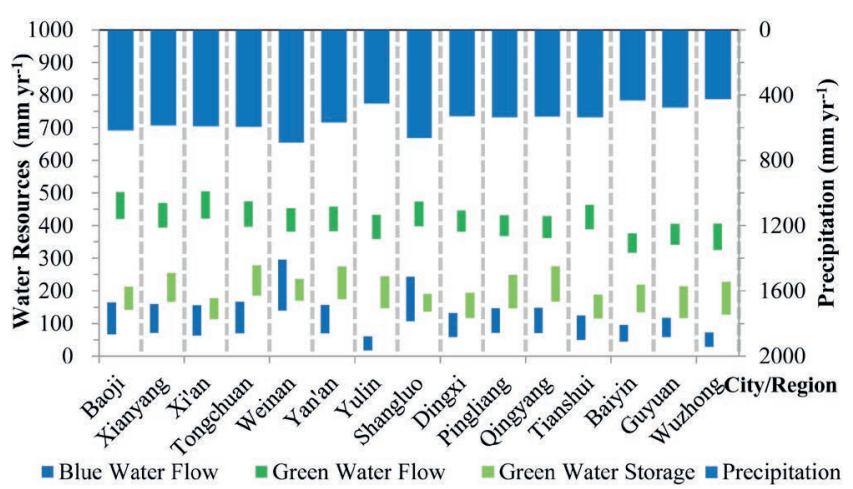

Fig. 6 Simulated average (1964-2008) annual city/regional precipitation, blue water flow, green water flow and green water storage at $95 \%$ prediction uncertainty.

\section{Water resources availability at city/region scale}

In order to show the difference in water resources components at the administrative level, the average (1964-2008) annual blue water flow, green water flow, and green water storage were aggregated for 15 cities/regions in the study area (Fig. 6). In general, cities/regions located near the outlet of the basin such as Weinan and Shangluo cities, show greater blue water flow, while the cities/regions in the headwater catchment of the basin such as Wuzhong and Yulin cities, show smaller blue water flow. The uncertainty ranges of average annual blue water flow are wider for some cities/regions, which have greater precipitation, and greater blue water flow. The greater the blue water flow is, the greater the uncertainty ranges are. Green water flow in the cities/regions located on the south bank of the Wei River are relatively greater than that in other cities/regions. Green water storage in Xi'an City shows the smallest value, while those of Tongchuan, Yan'an, Pingliang, and Qingyang in the north bank of the Wei River show greater soil water storage. This information can provide a basis for adjusting irrigation pattern in different irrigation districts, and is useful for domestic and industrial water users.

In order to estimate the uncertainties of water resources availability in each city/region during recent decades, HRU-based precipitation and the 95PPU ranges for blue water flow, green water flow, and green water storage were aggregated to obtain city/region-based values. Blue water flow and green water storage in all cities/regions exhibit a decreasing trend, especially for the 1990s. The uncertainty in green water flow was generally smaller than those for blue water flow or green water storage for the reasons explained above.

\section{CONCLUSION}

In this study, the calibrated SWAT model in combination with the GIS interface and SUFI-2 calibration and uncertainty analysis procedure was successfully applied to quantify the water resources availability, including blue water flow, green water flow as well as green water storage, in the WRB at the HRU spatial and monthly scales with uncertainty analysis. Water resources 
components were then aggregated at the river catchment and city/region scales. Major conclusions can be summarized as follows:

(1) Most parts of the WRB are experiencing serious blue water shortages, especially for the Loess Plateau in the north. The middle reaches of the Wei River and the lower reaches of the Beiluo River have relatively sufficient precipitation and green water resources to sustain the ecosystems, and the development of rain-fed agriculture in those regions.

(2) The inter-annual variability of blue water flow is large in the headwater catchment and middle reaches of the Wei River, and the headwater catchment of the Jing River. It decreased significantly from the 1960 s to the 2000 s, while the variation of green water flow and precipitation were smaller. The intra-annual variability of blue water flow shows large uncertainties in the flood season (July-October), which means unreliability of water availability in those months. The Loess Plateau maintains sufficient green water storage over the years.

(3) Some cities/regions near the outlet of the Wei River basin have a relatively large blue water flow, while the cities/regions in the headwater catchment of the basin have a small blue water flow. The quantity of green water flow in the cities/regions located in the south of the Wei River is relatively higher than that in other cities/regions. The green water storage in Xi' an City is notably small, while those of Tongchuan, Yan'an, Pingliang, and Qingyang cities in the north of the Wei River show rich soil water storage. The most southern part of the WRB (Guanzhong Plain), one of the most important grain production basements in China, is experiencing serious water scarcity.

The conclusions obtained in this study are valuable for efficiently utilizing and allocating water resources, and planning of cultivating seasons in the WRB, and could provide a reference for water resources management in the study area.

Acknowledgements This study is jointly supported by the National Natural Science Foundation of China (51309010, 51279005), and the Fundamental Research Funds for the Central Universities (2013NT46).

\section{REFERENCES}

Abbaspour, K. C., et al. (2007) Modelling hydrology and water quality in the pre-alpine/alpine Thur watershed using SWAT. Journal of Hydrology 333(2-4), 413-430.

Arnold, J. G., et al. (1998) Large area hydrologic modeling and assessment Part I: Model development. Journal of the American Water Resources Association 34(1), 73-89.

Falkenmark, M. (1995) Coping with water scarcity under rapid population growth. Conference of SADC Ministers, Pretoria.

Faramarzi, M., et al. (2009) Modelling blue and green water resources availability in Iran. Hydrological Processes 23(3), 486501 .

Gerten, D., et al. (2005) Contemporary "green" water flows: Simulations with a dynamic global vegetation and water balance model. Physics and Chemistry of the Earth 30(6-7), 334-338.

Jackson, R. B., et al. (2001) Water in a changing world. Ecological Applications 11(4), 1027-1045.

Liu, X., et al. (2009) Quantifying the effect of land use and land cover changes on green water and blue water in northern part of China. Hydrology and Earth System Sciences 13(6), 735-747.

Neitsch, S. L., et al. (2005) Soil and Water Assessment Tool Theoretical Documentation Version 2005. Grassland, Soil and Water Research Laboratory, Agricultural Research Service, Blackland Research Center, Texas Agricultural Experiment Station, Temple, Texas, $494 \mathrm{pp}$.

Rost, S., et al. (2008) Agricultural green and blue water consumption and its influence on the global water system. Water Resources Research 44, W09405, doi:10.1029/2007WR006331.

Schuol, J., et al. (2008) Modeling blue and green water availability in Africa. Water Resources Research 44, W07406, doi:10.1029/2007WR006609.

Yang, D. W., et al. (2004) Analysis of water resources variability in the Yellow River of China during the last half century using historical data. Water Resources Research 40, W06502, doi:10.1029/2003WR002763.

Zang, C. F., et al. (2012) Assessment of spatial and temporal patterns of green and blue water flows under natural conditions in inland river basins in Northwest China. Hydrology and Earth System Sciences 16(8), 2859-2870.

Zuo, D. P., et al. (2012) Spatiotemporal variations and abrupt changes of potential evapotranspiration and its sensitivity to key meteorological variables in the Wei River basin, China. Hydrological Processes 26(8), 1149-1160. 